\title{
In memoriam Norbert Herschkowitz (1929-2019)
}

Am 3. Juli durfte Norbert Herschkowitz, einige Wochen vor seinem 90. Geburtstag, zu Hause friedlich einschlafen. Nachdem er vor einigen Jahren eine Hirnblutung erlitten hatte, wurde er von seiner Ehefrau und Wegbegleiterin Elinore liebevoll zu Hause gepflegt.

Norbert Herschkowitz wurde 1929 in Basel geboren, wo er seine Schulzeit verbrachte und anschliessend erste Erfahrungen in der Berufswelt als Laborgehilfe bei Ciba-Geigy machte. Parallel dazu absolvierte er seine Matura, um ein Physikstudium an der ETH Zürich aufzunehmen. Bereits während dieser Zeit wurde er geprägt durch seine Arbeit mit schwerkranken Kindern am Röntgeninstitut. Die Überzeugung, dass diesen Kindern besser geholfen werden muss und könnte, wenn man nur genügend intensiv forschen würde, führte zum Wechsel des Studiengangs: Er studierte Medizin in der Schweiz, wobei ihm neben verschiedenen Jobs zur Finanzierung seines Traums bereits mehrere klinische Arbeitseinsätze in Spitälern in der Schweiz und in Israel die klinische Arbeit näherbrachten.

Schon früh fühlte er sich vom Ge-

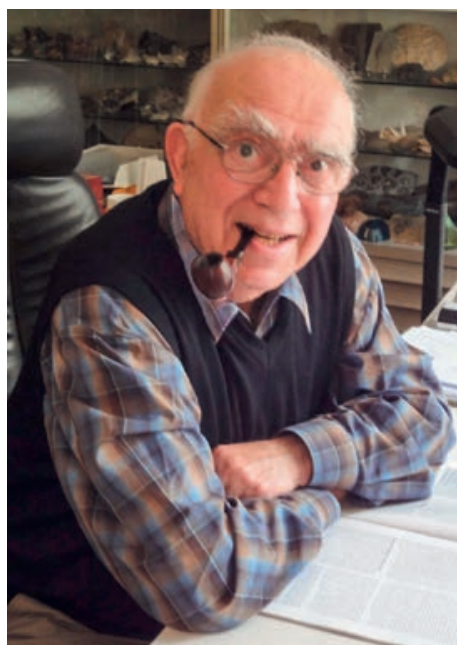

und anzutreiben. Die Arbeit gefällt mir sehr und ich geniesse jede Minute. Es ist wirklich notwendig, dass etwas geschieht, denn es gibt so viele Probleme mit diesen Kindern, die man bis jetzt einfach nicht lösen kann.»

Seine Ausbildung zum Kinderarzt durchlief er in $\mathrm{Bu}-$ enos Aires und in Basel, es folgten Forschungsauslandaufenthalte in London und an der Stanford-Universität in Kalifornien. Während dieser Zeit konnte er sich von den Möglichkeiten der damals noch neuen MRI-Technik überzeugen. Als er 1969 in die Schweiz und an die Kinderklinik in Bern zurückkehrte, engagierte er sich für die Anschaffung eines MRI-Geräts. Nachdem er zunächst als Abteilungsleiter tätig war, erhielt er 1982 die ordentliche Professur der Universität Bern. Er blieb neben seiner Forschungsarbeit klinisch tätiger Kinderarzt und widmete sich weiter den kleinen Patienten mit ihren Entwicklungsstörungen. Bis heute zeugt eine international bekannte pädiatrische Neuropsychologie an der Kinderklinik Bern von seinem Wirken.

Auch nach seiner Emeritierung liess ihn die Frage der Gehirnentwickheimnis über das Funktionieren des Gehirns angezogen. So schrieb er in den ersten Studienjahren in einem Brief an seine Mutter: «Was mich auch so interessiert: $\operatorname{der} \mathrm{Zu}$ sammenhang zwischen dem Gehirn und den inneren Organen, die Tätigkeit des Gehirns - des Organs, das uns zu Menschen macht.» Dieser Ausspruch als junger Medizinstudent wurde wohl zu seinem Berufsmotto. Mit Begeisterung widmete er sich insbesondere den biochemischen Substanzen im Gehirn und deren Funktionen. Ebenso früh entdeckte er seine Liebe zu Kindern, wobei er insbesondere Kindern mit einer Entwicklungsstörung helfen wollte. Er setzte sich dafür ein, dass diese Kinder besser in unser soziales Umfeld integriert wurden und nicht nur ihr Leben in Institutionen verbrachten. So gelang es ihm, dass geistig behinderte Kinder die Konfirmation in der Kirche erhalten durften. In einem weiteren Brief schrieb er an seine Mutter: «Ich bin ganz fest mitten in der Arbeit und rauche vor Aktivität. Es gibt unendlich viel zu planen, zu organisieren lung nicht ruhen. Er forschte weiter und öffnete sein Gebiet dem sich alternden Gehirn. Ausserdem versuchte er gemeinsam mit seiner Frau, dieses interessante und komplexe Wissen mithilfe von Büchern und diversen Vorträgen für die breite Öffentlichkeit verständlich zu machen. Während der Dekade des Gehirns von 1990 bis 2000 unterstützte er zudem viele Projekte, die das Wissen um unser Gehirn verbreiteten. Bis heute existiert die jährliche Woche des Gehirns in der Schweiz, und mit ihr lebt er weiter.

Norbert Herschkowitz durfte ein erfülltes Leben führen, und er hat dies voll Dankbarkeit mehrfach zum Ausdruck gebracht. Wir hoffen, dass diese Erkenntnis seiner Ehefrau, seinem Sohn, seiner Tochter und deren Familien Kraft für diesen schweren Abschied gibt.

Prof. Maja Steinlin Abteilungsleiterin Neuropädiatrie, Entwicklung, Rehabilitation, Universitätskinderklinik Bern 